\title{
QUALITY PARAMETERS OF INFORMATION SYSTEMS FOR BUSINESS IN THE CONTEXT OF DIGITAL TRANSFORMATIONS
}

\author{
Hasan Abu Ezza ${ }^{1}$, Anna.V. Shokhnekh², Victoria S. Telyatnikova ${ }^{2}$, Natalia S. Mushketova $^{3}$ \\ ${ }^{1}$ Damascus university of economic; Damascus, Syria/Plekhanov Russian University of Economics; \\ Moscow, Russian Federation \\ ${ }^{2}$ Volgograd State Socio-Pedagogical University Volgograd, Russia \\ ${ }^{3}$ Volgograd State University Volgograd, Russia
}

\begin{abstract}
The article provides a refined definition of "information system for business" as a coordinated set of material, non-material and human resourses components that is used to implement a set of procedures of forming an information resource as a quality product that meets the needs of external and internal users. According to the study, information technologies play a key role in the modern business environment. Many economic entities carry out their economical activities exclusively bye using communication-digital networks and functional software which provide the information necessary for effective business management. Resently, it has been proven that the communication and information technologies have become an integral part of any modern information systems, since they increase the level of business competitiveness during use the operational management information on time.These information technologies ensure the work's continuity of information systems for a long period of time with the possibility of quick adaptation of the business to the digital transformation's conditions, which reduce the formation's cost of information resources. The role of such components of information technology as software, databases and computer networks, which, in turn, are key components of high-quality information systems, is disclosed.
\end{abstract}

\section{Introduction}

Currently, the formation of information systems is carried out on the information and communication technologies basis.Information systems form an information resource, which considered as non-financial and intangible capital that meets the needs of interested users.Fully application of electronic information systems makes it possible to generate operational information for business in a short time, which ensures an increase in the quality of business analysis of the facts of economic life.

Wherefoe, electronic information systems can be considered as a platform for the formation of an information resource in both developed and developing countries.

The study shows that many innovative projects that are promising for information systems in the context of digital transformations are being developed on the basis of block- 
chain technologies.Opportunities for digital verification determine a new breakthrough in the electronic workflow of information systems for business.

\section{Discussions}

The ambition to improve the quality of information systems is a driver of continuous development of innovative technologies.Innovative technologies that improve the information system can improve the quality, which is characterized, first, by processing an expanded flow of incoming information, and secondly, by reducing analysis and synthesis time during operational processing. All the presented quality characteristics ensure the efficiency and reliability of the information processing. Improving the quality of information system production results is determined by the quality characteristics of the information product that meets the needs of not only business, but also users-consumers-third parties (Fig.1).

\begin{tabular}{|c|c|}
\hline $\begin{array}{c}\text { 1.The managers' ambition to improve the quality of information systems } \\
\text { technologies } \\
\text { 1.1. Development of innovative digital }\end{array}$ \\
\begin{tabular}{|c|c|} 
1.2. Mastering innovative digital \\
technologies
\end{tabular} \\
\hline $\begin{array}{c}\text { 2. Improving the quality of data processing in information systems } \\
\text { information }\end{array}$ & $\begin{array}{c}\text { 2.2 Reduction of analysis and synthesis } \\
\text { time during online data processing }\end{array}$ \\
\hline $\begin{array}{c}\text { 3. Improving the quality of information product (information reousrce) as a result of } \\
\text { information systems production }\end{array}$ \\
\hline $\begin{array}{c}\text { 3.1 Full support of business management } \\
\text { requests for effective decision making }\end{array}$ & $\begin{array}{c}\text { 3.2 Providing requests of users-consumers } \\
\text { (third parties) }\end{array}$ \\
\hline
\end{tabular}

Fig.1. Continuous development and mastering drivers of innovative technologies in conditions of improving information systemsquality

In conditions of high competition, having digital business technologieshelps to quickly anticipate the forecast future and more events' distant foresight based on information resourcediagnosticsing. Information and communication technologies have become an integral component for planning strategic business development, financial projects, marketing digital products and trading platforms, production design, accounting and reporting, and other areas of work.

When analyzing the essence of information systems, it is advisable to understand the ontology of the system itself. So, according to the philosopher Immanuel Kant: "scientific knowledge is a system in which the whole prevails over the parts" [4].

The systematic construction of phenomena, events, and processes has always been one of scientists' interest who saw the logic and simplicity of problem solving from the point of view of systemic position. In the 1940s, L. bertalanfi formed the doctrine of the "General theory of systems", in which (according to the research of E. A. Kapitonov) he identified two main features of the system: 
1) organization;

2) many types of connections.

In the construction of the "general theory of systems" L. Bertalanffy identified general principles and laws of systems' behavior, regardless of the nature of their structural elements and relations between them [5].

Currently, the ontology of the system has been extended by such representations as "two or more units that work together to achieve a certain goal". At the same time J. Hall believes that the system is "a set of components and elements that work together, consistently and purposefully to achieve specific goals" [7].

Research shows that the existing definitions are diverse, but have common features, including the following:

- a system consists of a set of material, non-material, human resources, or a combination of them, depending on system nature;

-the individual parts of the system are logically connected to each other, therefore they interact with each other through certain actions;

- each system has its own purpose and basis, which ensures the identification of the relationship between the system elements.

Defining the author's contribution to the ontology of the "system", it is possible to clarify its scientific representation as a coordinated set of resources and elements that interact with each other and provide a certain stability in a specific movement towards the goal in special conditions.

Research also shows the representations diversityof "information system" in international literature. Thus, M.Romney defines the information system as a system that "collects, records, stores and processes data in order to provide useful information for decisionmakers" [7].At the same time, M. Salehi and V. Rostami define the information system as "a framework that is used to coordinate human and material resources in order to transform input resources (data) into final results (information) and achieve the economic organization goal" [8]. According to L. Turner, the information system is "a set of elements and components (material and non-material) that work together to prepare data in a specific form which helps various management levels to achieve the economic organization goal" [13].

\section{Materialsandmethods}

The study used the methods of deduction, induction, analysis and synthesis, logic and analogy, as well as the method of a systems approach.

\section{Theresearchpart}

The final goal of any information system is to produce and provide useful information for interested users who make management decisions. "Useful information" in this aspect is presented as a high-quality information resource.

Consequently, the information systemontology for business is represented as a set of information systems, consisting of modern computer technologies, software, material and personnel tools.

Research shows that the key element of information systems for business is human resources that set the mission, goals, objectives, principles, functional features and performance parameters. Human resources "are responsible for its work, they must have a high level of training, qualifications, experience, scientific and practical skills in the field of information systems ...» [8]. 
However, there is a point of view that material resources are more important than human resources, which make it possible to process information flowsquickly and accurately [6].

In turn, there is a claim that the intellectual resources in the form of software have play role in improving information system quality. Thus, N. B. Sayles believes the softwaredirects the system's material resources to obtain specific results to achieve the system's goals [9].

Also N.A. Bagranoff, M.G. Simkin, S.N. Carolyn argues that database plays krole in the design of information system for business. The database provides access to current and archived data, accumulates information and integrates information subsystems, and allows exchangeing of data from one source [2].

Thus, we can conclude that the information system for business is built, firstly, on human resources that ensure the system operation and form the goals, objectives, principles, functional features of its work, and secondly, on material resources, representation computer technologies, thirdly, on non-material resources such as software, licenses for the right to use intellectual property, fourthly, on effective products of information resources, including operational, current, forecast, historical reporting for decision-making purposes.

The study shows that each component of the information system for business has its own functional feature, which is determined by the needs of business and users-consumers to make significant decisions, the quality will be determined by the level of security in the necessary information.

Consequently, the use of information systems for business is conditioned by the need to transform data into "useful information", which should be characterized as qualitative.

In general, the structure of information system for business integrates information technology and human resources: computer and communication networks and the knowledge of specialists and experts (Fig. 2).
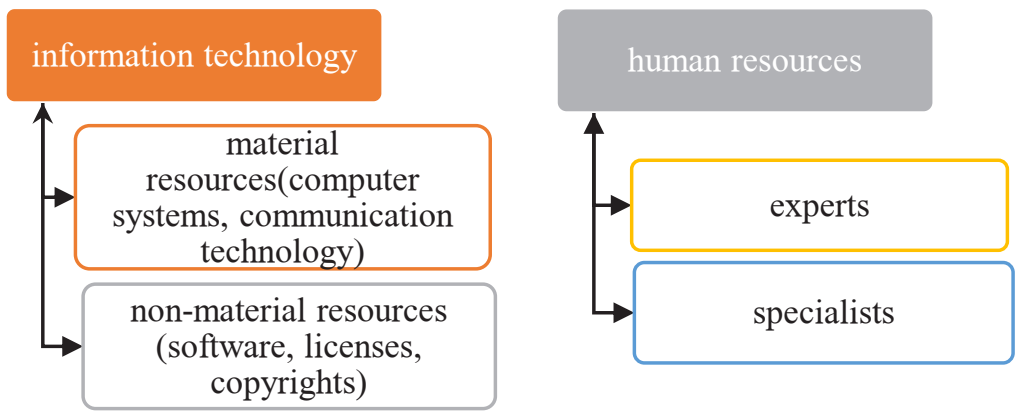

Fig.2. General view of the structure of an information system for business

Information technologies are determined by a set of basic methods used in computer information systems and their practical applications, such as hardware, software, databases, communication networks and information tools for collecting, processing, storing and disseminating information.

In general, we can say that information technology is a set of tools of both material and technical methods that increase work efficiency by receiving, processing, searching and transmitting information in electronic form through computer systems, software and communication networks.

The study shows that information systemsevolution is like a multi-stage change in the structural operating methods. Consequently, the development of information systems has 
gone through many rounds: from manual, partially automated, fully automated data processing to communication-digital exchange using satellites.

The total application of the Internet is consideredvery important for the development of information systems. It leads to many innovations in the field of electronic data interchange and the emergence of ERP systems. The development of: 1) databases becomes essential; 2) coding systems (bar coding) as a technological tool that allows a quickly enter of information, saving time and reducing costs in during data entry; 3 ) distributed ledger technologies (DLT) and Just in Time (JIT) systems [12].

Accordingly, information technologies are used in information systems to improve the quality based on high speed of inputing, processing, storageing and retrieval of information, accuracy of data processing, as well as constant monitoring information resourceforming for making management decisions.

Currently, aspects of the quality of information systems for business are relevant, which is manifested in a widespread distrust of the relevance and usefulness of information in the context of digital transformations. The anxiety of information resources users is confirmed by many empirical studies that reflect the decline in quality from the standpoint of abilitylack to predict the future results of foresight business development (including the profitability of investment projects and shares).

The quality parameters of information systems should be analyzed during the period of a difficult situation for the business, in which the economic entity deviates from the goal and does not achieve the results expected from the management system. Shifting the focus in the management system to lower priority tasks also allows us to judge the decline in the quality of information systems as a producer of an information resource.

An interesting scientific study was conducted by I. Ansoff, in which the quality characteristics were considered through the prism of turbulence in the external environment [1]. It was proposed to use a five-factor model of an economic entitystability to measure qualitative characteristics that reflected: changes; extensions; repetitions; discontinuous movement; surprise [11].

\section{Effectivepart}

Research shows that currently, in the context of digital transformation, all the proposed quality parameters should be integrated into a high-quality information system. Given that the very concept of entrepreneurial activity is interpreted as a specific type of social behavior that is implemented in a system of market uncertainty and risks, aimed at obtaining benefits in the process of using economic resources (land, labor, capital), it is necessary to be prepared for possible losses (insolvency). To ensure the quality of information systems, it is necessary to identify and minimize such risks as: entrepreneurial; resource depletion; market demand; credit; investment; management [10].

The security is an indicator of information system quality. In the digital economy, there are high information and economic risks that threaten the stable and sustainable of information systems. The absence of risk is indicatingto a high level security of information system, which can form a high-quality information resource for business.

\section{Conclusion}

In conclusion, it is important to note that a high-quality information system allows to "extract" the information about the transformation of the environment and timely determine the needs of society. The lack of timely information will not allow the business to adapt to the changed conditions, and, consequently, give way to more informed and prepared competi- 
tors. The lack of timely information will not allow the business to adapt to the changed conditions, and, consequently, give way to more informed and prepared competitors. Consequently, economic entities should set parameters for the quality of information systems that will respond in a timely manner and expose risks.

\section{Acknowledgements}

The article was funded by the Russian Foundation for Basic Research "Cognitive approach to theoretical and methodological foundations of strategic development of small businesses in the digital economy system taking drift risks into account" No. 18-010-01210 - A.

\section{References}

1. H.I. Ansoff, Strategic management, (1979)

2. N.A.Bagranoff, M. G. Simkin, S. N., Carolyn. Core Concepts in Accounting Information Systems (2009)

3. J. A. Hall, Accounting Information Systems, (2015)

4. I. Kant, Criticism of pure reason, (1998)

5. E.A.Kapitonov, Sociology of the XX century, 141 (1996)

6. K. C. Laudon, J. P.Laudon, Management Information Systems - Managing the Digital Firm (2016)

7. M. B. Romney, P. J. Steinhart, Accounting Information Systems, (2017)

8. M. Salehi, V. Rostami, A. Mogadam, Economics and Finance Journal, 2, 186 (2016)

9. N.B. Sayles, Introduction to Information Systems for Health Information Technology, (2018)

10. A.V.Shokhnekh, International Journal for Quality Research, 3, 655 (2019)

11. G.I. Sidunova, A.V. Shokhnekh, The Future of the Global Financial System: Downfall or Harmony, "Lecture Notes in Networks and Systems" Cham, Switzerland, 657 (2019)

12. S. Soudani, Research Journal of Finance ans Accounting, 11, 17 (2013)

13. L. Turner, A. Weickgenannt Accounting Information Systems: Controls and Processes. (2016) 